\title{
Hypercalcaemia and parathyroid hyperplasia associated with renal adenocarcinoma
}

\author{
A. JunG \\ B.Sc., M.D. \\ R. Millet \\ M.D. \\ PH. SCHNEIDER \\ M.D.
R. J. WALTON*
M.R.C.P.

\begin{abstract}
Department of Medicine and Institute of Pathology, University of Geneva, Switzerland and Nuffield Department of Orthopaedic Surgery, University of Oxford
\end{abstract}

Summary

A patient with recurrent renal adenocarcinoma had progressive hypercalcaemia associated with hypophosphataemia and inappropriately high circulating levels of immuno-reactive parathyroid hormone. At post-mortem, there was no evidence of bone metastases but hyperplasia of all four glands was found. It is suggested that the malignant tissue was producing a parathyroid-stimulating substance.

\section{Introduction}

Hypercalcaemia in patients with malignant disease is usually due to bone metastases but is sometimes associated with inappropriately high levels of immuno-reactive parathyroid hormone in the serum (Tashjian, Levine and Munson, 1964; Sherwood et al., 1967; Roof et al., 1971). In most such cases, this immuno-reactive parathyroid hormone seems to be produced by the malignant tissue but occasionally there is an associated parathyroid adenoma (Dent and Watson, 1964; Katz et al., 1970; Kaplan et al., 1971) or, rarely, parathyroid hyperplasia (Case Records of the Massachusetts General Hospital, 1957, 1964; Stone, Waterhouse and Terry, 1961). Previously reported associations of malignant disease with parathyroid hyperplasia have all been in patients with squamous cell carcinoma of the bronchus. This report is of a patient with parathyroid hyperplasia and renal adenocarcinoma.

\section{Case report}

A 29-year-old man was admitted to hospital because of haematuria due to a tumour of the right kidney. Nephrectomy was performed and the histological diagnosis was adenocarcinoma (Fig. 1). Total plasma calcium (corrected for plasma protein concentration) and inorganic phosphate were normal

\footnotetext{
* Correspondence: Dr R. J. Walton, Nuffield Orthopaedic Centre, Oxford OX3 7LD.
}

at 9.6 and $3.5 \mathrm{mg} / 100 \mathrm{ml}$ respectively. Eighteen $\mathrm{N}$ months later he was re-admitted with a painful masso in the right hypochondrium. Plasma calcium had risen to $10.4 \mathrm{mg} / 100 \mathrm{ml}$ and plasma phosphate was now $3.1 \mathrm{mg} / 100 \mathrm{ml}$. A second operation was decidedo against and he was treated with antimitotic drugs. Three weeks later, he was hypercalcaemic, plasma 7 calcium being $14.6 \mathrm{mg} / 100 \mathrm{ml}$ and the plasmao phosphate $2 \cdot 1 \mathrm{mg} / 100 \mathrm{ml}$. Skeletal X-rays were normal. But 3 months later, despite treatment with corticosteroids, plasma calcium had risen further $\AA_{0}-$ $18.6 \mathrm{mg} / 100 \mathrm{ml}$. Plasma phospate was now $1.8 \mathrm{mg} / \sigma$ $100 \mathrm{ml}$, creatinine $1.7 \mathrm{mg} / 100 \mathrm{ml}$, urea $46 \mathrm{mg} / 100$ के and alkaline phosphatase $53 \mathrm{iu} / 1$. Serum immuno-o reactive parathyroid hormone (assayed according to the method of Arnaud, Tsao and Littledike, 1971) was $0.5 \mathrm{ng} / \mathrm{ml}$, the upper limit of normal being 0.40 $\mathrm{ng} / \mathrm{ml}$ when plasma calcium is within the normal range. Despite rehydration and infusions of sodium $\overrightarrow{\overrightarrow{0}}$ phosphate, the patient died one month later $\left(22^{3}\right.$ months after admission).

At post-mortem, a large retroperitoneal tumour? was found, the microscopic appearance being the을 same as that of the original renal lesion. No bone metastases were found either on macroscopic or microscopic examination, but there was increased osteoclastic activity and trabecular remodelling. Allo four parathyroids were enlarged (total mass $410 \mathrm{mg}$ ) with generalized chief cell hyperplasia (Fig. 2).

\section{Discussion}

There are several reasons for believing that this ${ }^{\circ}$ patient's rapidly progressive hypercalcaemia was due to hyperparathyroidism and not to bone metastases. N Firstly, there was no evidence of bone metastaseso during life or post mortem. Secondly, hypercalcaemia due to bone metastases is often accompanied by $\frac{0}{\bar{C}}$ hyperphosphataemia because increased bone re- + sorption leads to au increased rate of removal of both calcium and phosphate from bone, and alsoo 


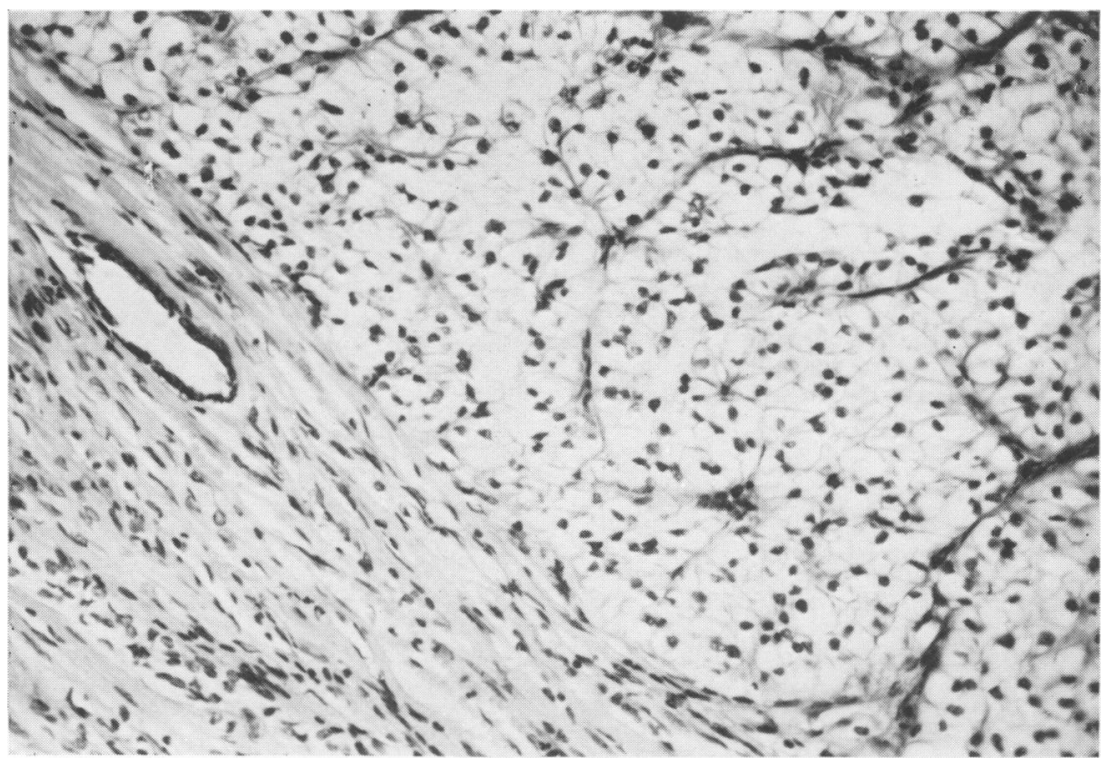

FIG. 1. Operative specimen of renal adenocarcinoma, $\times 144$.

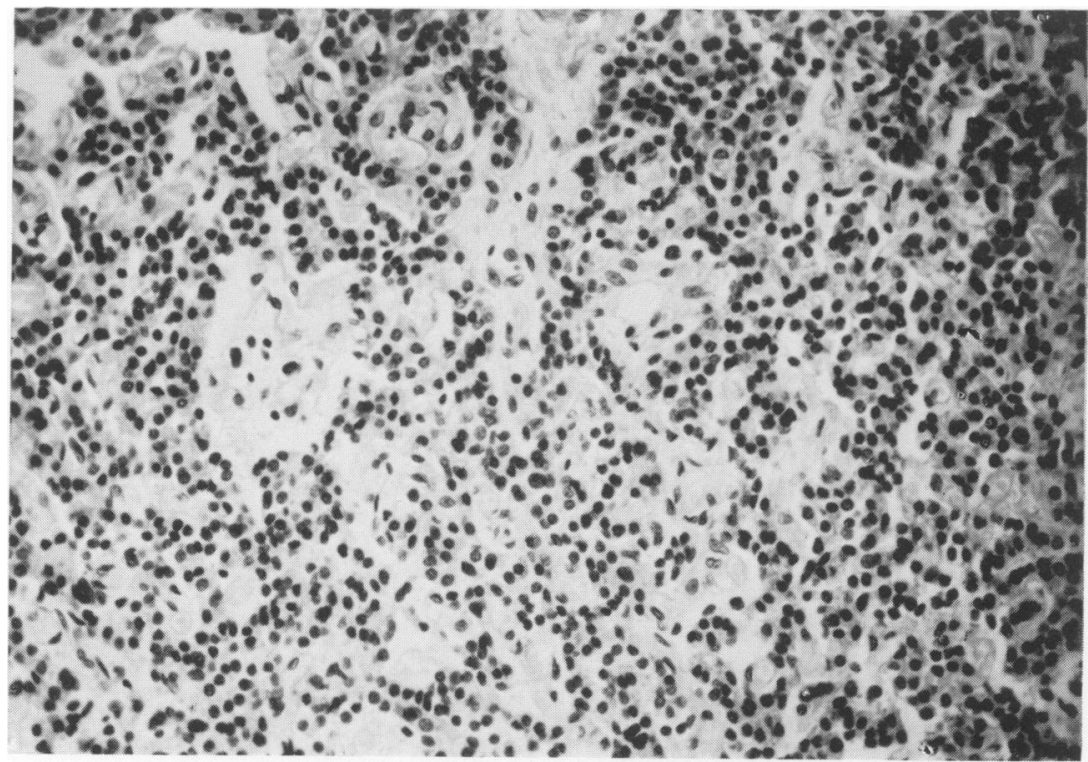

FIG. 2. Post-mortem specimen of parathyroid hyperplasia, $\times 144$.

because the hypercalcaemia leads to parathyroid suppression with a consequent increase in renal tubular resorption of phosphate. Thirdly, there was clear evidence of parathyroid overactivity: the serum concentration of immuno-reactive parathyroid hormone was increased and parathyroid hyperplasia was found at post-mortem.
The association of renal adenocarcinoma and parathyroid hyperplasia in this patient could obviously be fortuitous, but the similarity in time course between the growth of the tumour and the development of the features of hyperparathyroidisin suggests that the malignant tissue was producing a parathyroid-stimulating substance. A speculative 
possibility is that this substance was a metabolite of vitamin $D$, since it is known that the normal kidney produces a number of such metabolites and it is conceivable that one or more of them might be capable of stimulating parathyroid activity.

\section{Acknowledgments}

We thank Professor B. Courvoisier, Professor Y. Kapanci, Dr J. Cox, Dr J. J. Widman and Dr N. Reverdin for their helpful comments, Dr J. Fischer for the radio-immunoassay of parathyroid hormone, and Mr M. Denkinger and Mr J. C. Rumbeli for technical assistance. This work has been partly supported by Grant 4.0541.72 from the Swiss National Fund.

\section{References}

Arnaud, C.D., Tsao, H.S. \& Littledike, T. (1971) Radioimmunoassay of human parathyroid hormone in serum. Journal of Clinical Investigation, 50, 21.

Case Records of the Massachusetts General Hospital (1957) Case 43 151. New England Journal of Medicine, 256, 750.

Case Records of the Massachusetts General Hospital (1964) Case 21-1964. New England Journal of Medicine, 270, 898.
DENT, C.E. \& WATSON, L.C.A. (1964) Hyperparathyroidism and cancer. British Medical Journal, 2, 218.

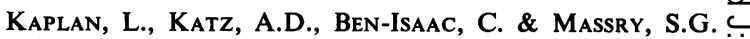
(1971) Malignant neoplasms and parathyroid adenoma. Cancer, 28, 401.

Katz, A., Kaplan, L., Massry, S.G., Heller, R., Plotkin, ఫ D. \& KNIGHT, I. (1970) Primary hyperparathyroidism in patients with breast carcinoma. Archives of Surgery, 101, 582.

Roof, B.S., Carpenter, B., Fink, D.J. \& Gordan, G.S. (1971) Some thoughts on the nature of ectopic parathyroid hormones. American Journal of Medicine, 50, 686.

Sherwood, L.M., O'Riordan, J.L.H. AURBaCh, G.D. \& PoTTS, J.T. (1967) Production of parathyroid hormone by $\vec{\omega}$ non-parathyroid tissue. Journal of Clinical Endocrinology and Metabolism, 27, 140.

Stone, G.E., Waterhouse, C. \& Terry, R. (1961) Hypercalcemia of malignant disease: case report and a proposed mechanism of etiology. Annals of Internal Medicine, 54, $\mathrm{N}$ 977.

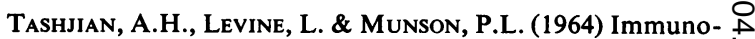
chemical identification of parathyroid hormone in non- $\overrightarrow{-}$ parathyroid neoplasms associated with hypercalcemia. Journal of Experimental Medicine, 119, 467. 